\title{
Joint impact of rainfall and tidal level on flood risk in a coastal city with a complex river network: a case study of Fuzhou City, China
}

\author{
J. J. Lian, K. Xu, and C. Ma \\ State Key Laboratory of Hydraulic Engineering Simulation and Safety, Tianjin University, Tianjin 300072, China \\ Correspondence to: C. Ma (mac_tju@126.com)
}

Received: 6 May 2012 - Published in Hydrol. Earth Syst. Sci. Discuss.: 12 June 2012

Revised: 22 January 2013 - Accepted: 24 January 2013 - Published: 14 February 2013

\begin{abstract}
Coastal cities are particularly vulnerable to flood under multivariable conditions, such as heavy precipitation, high sea levels, and storms. The combined effect of multiple sources and the joint probability of extremes should be considered to assess and manage flood risk better. This paper aims to study the combined effect of rainfall and the tidal level of the receiving water body on flood probability and severity in Fuzhou City, which has a complex river network. Flood severity under a range of precipitation intensities, with return periods (RPs) of $5 \mathrm{yr}$ to $100 \mathrm{yr}$, and tidal levels was assessed through a hydrodynamic model verified by data observed during Typhoon Longwang in 2005. According to the percentages of the river network where flooding occurred, the threshold conditions for flood severity were estimated in two scenarios: with and without working pumps. In Fuzhou City, working pumps efficiently reduce flood risk from precipitation within a 20-yr RP. However, the pumps may not work efficiently when rainfall exceeds a 100-yr RP because of the limited conveyance capacity of the river network. Joint risk probability was estimated through the optimal copula. The joint probability of rainfall and tidal level both exceeding their threshold values is very low, and the greatest threat in Fuzhou comes from heavy rainfall. However, the tidal level poses an extra risk of flood. Given that this extra risk is ignored in the design of flood defense in Fuzhou, flood frequency and severity may be higher than understood during design.
\end{abstract}

\section{Introduction}

Flood is the most frequently occurring natural disaster in the world that poses high physical risk and economic dam- ages (Chang et al., 2008; Adelekan, 2010). Coastal cities with large impervious areas are vulnerable to flood caused by a single source or several sources acting in combination (Dawson et al., 2008; Archetti et al., 2011). In China, most coastal cities, such as Fuzhou, Wenzhou, and Shanghai, are located in low-lying areas with a complex river network and a receiving water body downstream, whose tidal level is affected directly or indirectly by upstream flow and tidal effect. In these cities, episodes of flood are mainly river inundations caused by large amounts of rain run-off, which the river network cannot accommodate. High levels of the receiving water body downstream aggravate the inundation by impeding the discharge of tide-locking and drainage pumps. Given the high spatial concentration of people and values in cities, even small-scale floods may lead to considerable damage. In extreme cases, urban floods can result in disasters that set back urban development by years or even decades. Therefore, more attention to international flood management should be paid to develop an integrated system of flood risk management (Plate, 2002; Samuels et al., 2006; Merz et al., 2010). For a coastal city, flood risk is influenced by rainfall, the tidal level of the receiving body of water, and the drainage system, including the drainage and river networks and other drainage facilities. Dense populations and intensive economic activities due to urbanization increase flood risk. Although the existing drainage system can cope with some rainfall, floods may still occur when rainfall or the tidal level is higher than the standard or threshold. The threshold values for flood severity and joint probability, which are keys to the design of future drainage systems, should be considered to assess and manage flood risk.

In recent years, the scope of flood risk assessment has extended from the national level (Hall et al., 2005; Ni et al., 
2010 ) to river basins (Rulli and Rosso, 2002; Kok and Grossmann, 2009; te Linde et al., 2011; Mazzorana et al., 2012), urban areas (Hadjimitsis, 2010; Wang et al., 2010; Pathirana et al., 2011), and even to some specific sites (Dawson et al., 2005; Ernst et al., 2010; Youssef et al., 2010). Hydrodynamic models are widely applied in flood risk assessment. Recent developments in computational technology facilitate the development of a hydrodynamic model for a complex river network for flood drainage. Some numerical simulation tools for urban river networks, such as MIKE 11 (Ngo et al., 2007) and HEC-RAS (Knebl et al., 2005; Lee et al., 2006; Rodriguez et al., 2008; Fan et al., 2009), have been widely adopted to model the operational conditions of complex river systems. These tools not only represent flood characteristics for the surface-river interaction mechanism but also reflect the effects of various flood controls and urban infrastructure, such as dykes, culverts, bridges, pumping stations, etc. Traditionally, the study of flood risk assessment in urban areas always focuses on the physical aspects, such as the extent and depth of inundation and the resulting losses (Apel et al., 2008). Flood risk assessment is developed based on a specific simulated scenario, which may not effectively reflect the threshold conditions for flood severity or the joint risk probability of the multivariate conditions leading to flood.

Multivariable probability models, such as the normal distribution, Gumbel-mixed (Yue et al., 1999), exponential (Bacchi et al., 1994), gamma distribution (Skaugen, 2007), meta-Gaussian (Kelly and Krzysztofowicz, 1997), and Farlie-Gumbel-Morgenstern (FGM) models (Long and Krzysztofowicz, 1992), are often used to study joint risk probability. The measures of dependence among random variables in these models involve only second-moment statistics and can thus capture a limited aspect of the dependence (AghaKouchak et al., 2010). On the other hand, copulas can describe nonlinear dependencies among the variables. In fact, for copulas, the marginal properties and dependence structure of the variables can be investigated separately (Grimaldi and Serinaldi, 2006). In recent years, copula-based models have been widely employed to estimate multivariate distribution in hydrological applications (De Michele et al., 2007; Renard and Lang, 2007; Bárdossy and Pegram, 2009; Balistrocchi and Bacchi, 2011; van den Berg et al., 2011). The widely used copulas for hydrological analysis include the Gaussian, $t$, Clayton, Frank, and Gumbel copulas.

The purpose of this paper is to investigate the threshold conditions for flood severity and joint flood probability in a coastal city under the combined impact of rainfall and tidal level. The study would provide significant support for decision making in flood defense design and flood risk management. The case study area, Fuzhou City, is described in Sect. 2. In Sect. 3, the joint impact and risk probability under the combination of rainfall and tidal level are investigated. A complex river network model was developed to analyze the joint impact of rainfall and tidal level on flooding probability. An analysis method for joint risk probability was selected

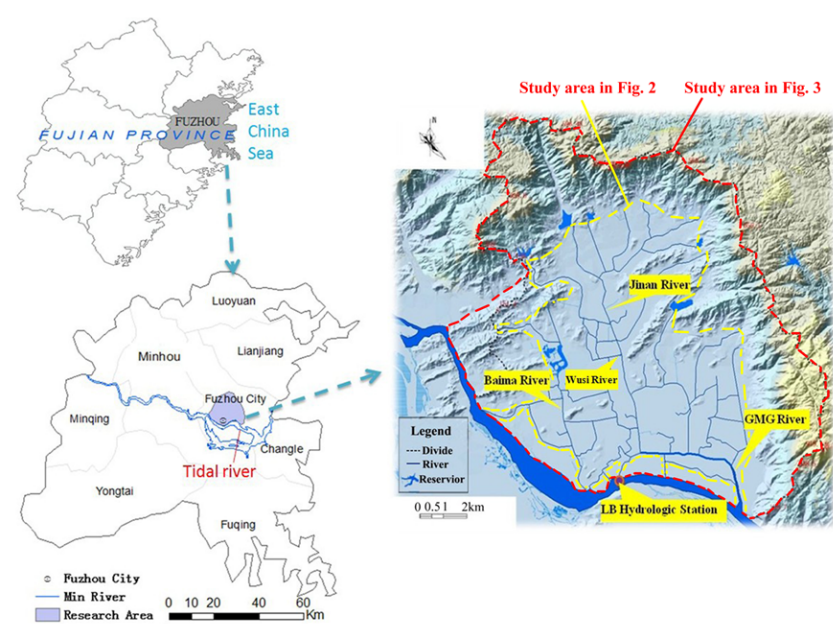

Fig. 1. Location map of the study area and its terrain map showing district boundaries along with the complex river network.

by comparing between five different copulas. The results and discussion are presented in Sect. 4. Conclusions are given in Sect. 5.

\section{Case study area}

Fuzhou, the city chosen as the case study, is located on the southeast coast of China and surrounded by mountains in the north, west, and east and by a tidal river, the Min River, in the south (Fig. 1). The majority of land in Fuzhou is a mixed hilly area of $66.72 \mathrm{~km}^{2}(41.8 \%)$ and a plain region of $90.05 \mathrm{~km}^{2}(58.2 \%)$. In the urban area, dozens of rivers and conduits form a complex river network with some converging and diverging branches and closed loops. The total length of the rivers is approximately $32 \mathrm{~km}$, and the river network could be divided into two regions: the west region with the main drainage channel, Baima River, and the east region with the Jinan and Guang Ming Gang (GMG) Rivers. Seven tide gates and three pump stations for flood discharge and protection are located close to the outlet of the rivers. A single hydrologic station, called LB, which can measure precipitation, discharge, and water level, is located by the Min River. According to LB hydrologic station records, the warning level of the Min River at this station is $6 \mathrm{~m}$, and the highest river level, recorded on 7 July 1992, is $9.53 \mathrm{~m}$. The data were measured using the Luo Zero Vertical Datum of China, which equals the National Vertical Datum 1985 plus 2.179 m (National Vertical Datum 1985 renders the mean sea level of the Yellow Sea as $0.0 \mathrm{~m}$ ).

Given the maritime subtropical monsoon climate, the mean annual temperatures of Fuzhou range from $16^{\circ} \mathrm{C}$ to $20^{\circ} \mathrm{C}$, and the mean annual precipitation is approximately $1320 \mathrm{~mm}$. Heavy rains often abruptly occur during summer seasons, with extreme rainfall during typhoons. According to historical records (1949-2011), Fuzhou (including the city 
proper and counties) has been struck by typhoons 39 times and 56 times by tropical cyclones, the main sources of heavy rains. In recent years, the river network and its urbanized coast have been particularly vulnerable to floods during typhoons. The reported direct reason for the disasters is the inundation of the river system under the effect of intense rainfall and high tidal levels downstream. The disasters disrupt the residents' daily activities and cause huge socio-economic losses. For example, the catastrophic flood caused by Typhoon Longwang with a 1-h maximum rainfall of $118 \mathrm{~mm}$ in 2005 caused the inundation of a $13.69 \mathrm{~km}^{2}$ area, resulting in over 62 dead people, 24 missing, and 120000 evacuated and a direct economic loss of 2.2 billion yuan.

\section{Data and methods}

\subsection{Data collection}

The data used for the hydrodynamic simulation model and flood risk analysis include precipitation and tidal level records; the 1:10000 digital elevation model (DEM) data for Fuzhou with a 5-m resolution; the details of hydraulic structures, including tide gates and drainage pumps; the distribution and drainage capacity of drainpipes; the profiles of river cross sections; and the roughness coefficients of the rivers provided by the relevant authority.

The precipitation and tidal levels measured by the Luo Zero Vertical Datum of China were recorded from 1952 to 2008 by the LB hydrologic station. The former includes maximum rainfalls at different times $(10 \mathrm{~min}, 30 \mathrm{~min}, 1 \mathrm{~h}, 3 \mathrm{~h}, 6 \mathrm{~h}$, $12 \mathrm{~h}$, and $24 \mathrm{~h}$ ) and a typical precipitation event. The latter includes the annual maximum tidal levels, the highest tidal levels within the day of annual maximum 24-h rainfalls, and a typical tide event.

\subsection{Complex river network modeling}

The hydrodynamic simulation model of the complex river network was developed through the well-known HEC-RAS tool with a user-friendly interface for data input and visualization of results (Fig. 2). In the model, 1713 cross-sectional profiles were made with distances of $20 \mathrm{~m}$ to $50 \mathrm{~m}$ between consecutive cross sections. Manning roughness coefficients with a calibrated range of 0.025 to 0.045 were provided by the Department of River Management of Fuzhou. For the tide gates and drainage pumps, the scheduling rules were set in the model with several parameters, such as the geometric properties of gates and the sluice discharge coefficient.

The boundary conditions for the model include two types: inflow and outlet boundary conditions. Five steps were carried out to translate the original data into flow and stage hydrographs as the boundary conditions: (a) selecting a typical precipitation event and a typical tide event; (b) deriving design standard rainfalls (with return periods (RPs) of 5,10 , 20,50 , and $100 \mathrm{yr}$ ) and tidal levels from an annual maximum

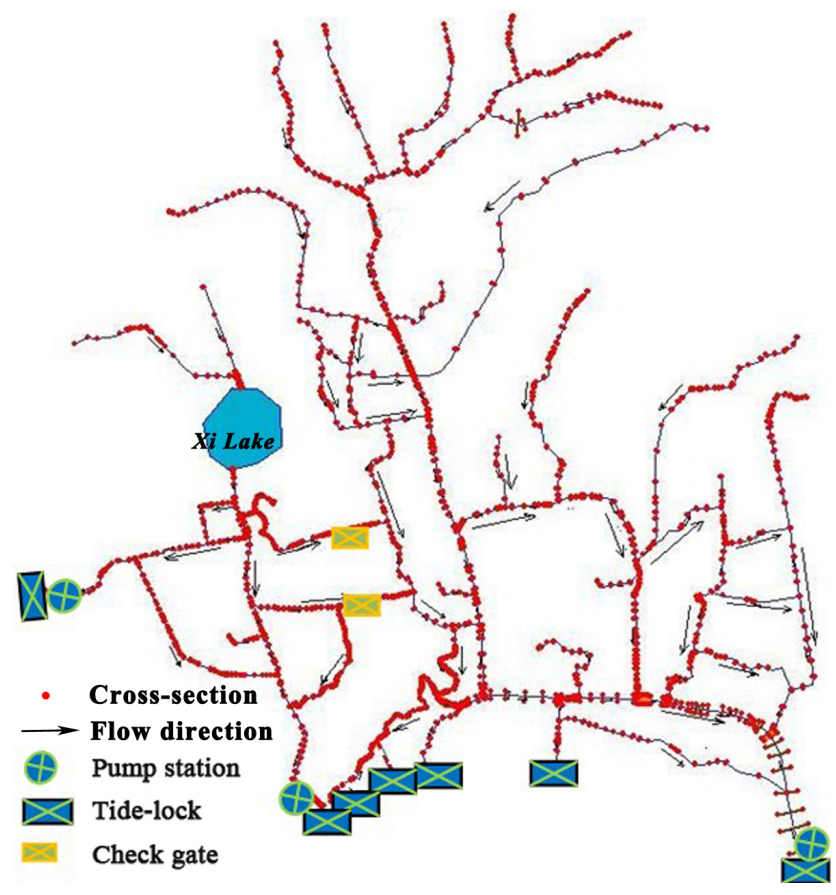

Fig. 2. River network model established by HEC-RAS with three pump stations, seven tide gates and two check gates.

24-h precipitation series and an annual maximum tidal level series from 1952 to 2008, respectively; (c) obtaining design rainfall processes based on design standard rainfalls and the typical precipitation event, as well as tidal level hydrographs according to design standard tidal levels and the typical level hydrograph; (d) estimating the flow hydrographs according to design rainfall processes; and (e) inputting the flow and the tidal level hydrographs as the boundary conditions for the model. The specific methods for the calculation and set of each type of boundary conditions are introduced hereafter.

\subsubsection{Inflow boundary conditions}

The inflow boundary conditions include two types: the flow hydrographs of rainfall run-off from northern mountainous areas and of rainfall run-off in urban areas.

For the calculation of the flow hydrographs of rainfall run-off from northern mountain areas, the mountain areas were divided into several sub-catchments using ArcSWAT (Fig. 3). Then, the flow hydrograph of each sub-catchment was calculated through a rainfall run-off model, the Xinanjiang model (Ren-Jun, 1992; Hu et al., 2005; Cheng et al., 2006), which takes the design rainfall processes as its input data. The northern mountain areas were divided into 16 subcatchments from $\mathrm{n} 1$ to $\mathrm{n} 16$, and the flow hydrograph of each sub-catchment outlet was taken as inflow boundary conditions of the model.

Three main steps are followed for the flow hydrographs of rainfall run-off in urban areas. First, the urban areas are 


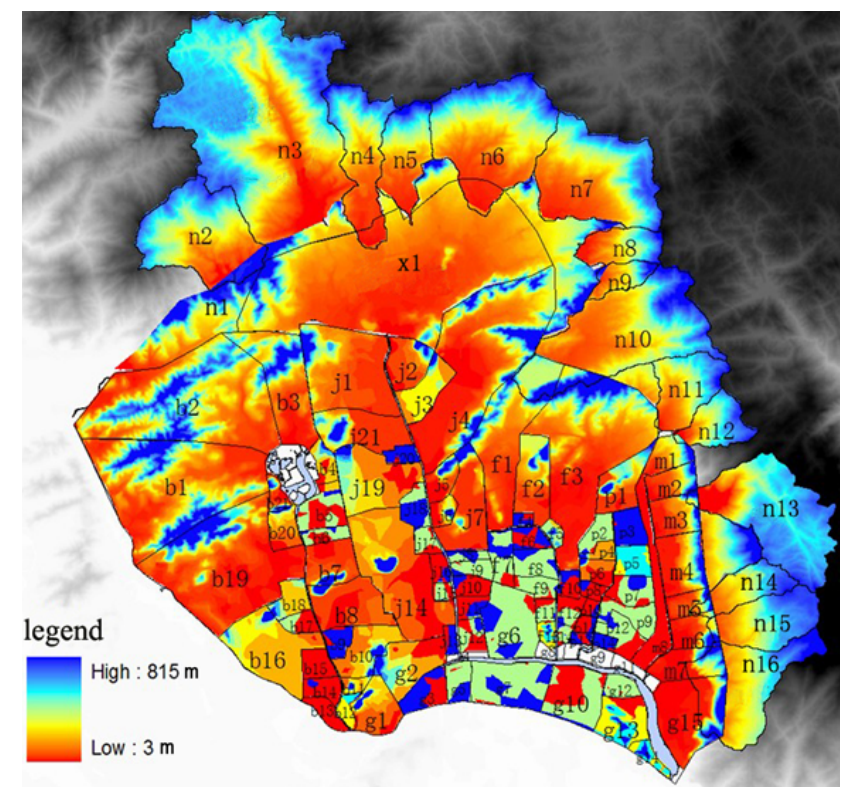

Fig. 3. Sub-catchment division and numbering with digital elevation nephogram for flood hydrographs. Different letters represent different areas ( $n$ representing northern mountain areas; $\mathrm{p}$ representing Pingdong River areas; $b$ representing Baima River areas; j representing Jinan River areas; g representing GMG River areas; m representing Moyang River areas; f representing Fengban River areas; and $\mathrm{x}$ representing Xindian areas).

divided into different sub-catchments according to drainpipe distribution and DEM data. The surface run-off process for a sub-catchment is simplified as a triangle process (the dashed line in Fig. 4). Peak discharge $Q$, the summit point of the triangle, is calculated using the rational method (Guo, 2001). According to the rational method, $Q$ is determined by the average intensity of rainfall for the time of concentration, the runoff coefficient, and the watershed drainage area. The total volume of run-off $W$, the area of the triangle, is derived using the urban rainfall run-off model. Accordingly, the duration of the surface run-off $T$ is equal to two times of $W$ divided by $Q$. Finally, because of the drainage capacity $\left(Q_{\mathrm{p}, \max }\right)$ of the drainpipes, the outflow process of the drainpipe network in a sub-catchment is modified as the solid line in Fig. 4. In the sub-catchments without drainpipes, the outflow process flowing directly into the river is the same as the surface runoff process.

\subsubsection{Outlet boundary conditions}

The outlet boundary conditions mainly consist of a design tidal level hydrograph at each outfall and operations of tide gates and drainage pumps. In the model, the opening of tide gates and drainage pumps is regulated automatically based on the upstream water level. When this level exceeds the tidal level of the outfall, tide gates will be opened so that the drainage system can communicate with the receiving body

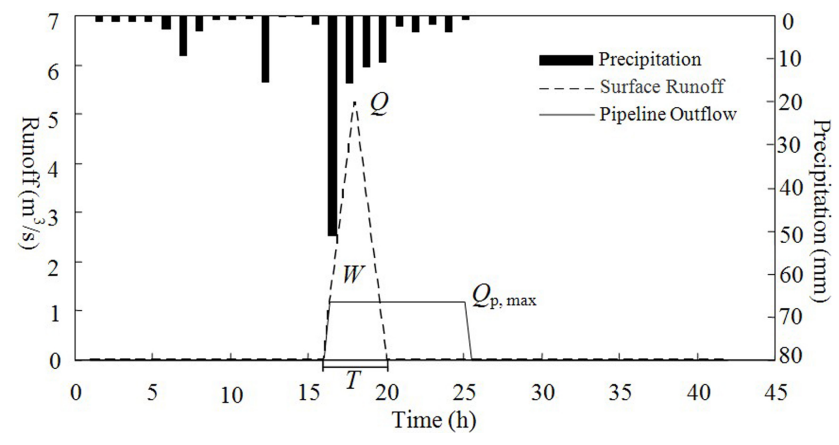

Fig. 4. Surface runoff process and pipeline outflow process of a subcatchment in an urban area. $Q$ is the peak discharge, shown as the summit point of the triangle. $W$, the area of the triangle, is the total volume of run-off. $T$ is the duration of the surface run-off. $Q_{\mathrm{p} \text {, max }}$ is the drainage capacity of the drainpipes.

of water. When the water level upstream is higher than the pump's trigger elevation for turning on, the drainage pumps will work.

\subsection{Analysis of joint impact of rainfall and tidal level on flooding}

The joint impact of rainfall $h$ and tidal level $z$ on flooding is estimated using flood severity as the evaluation index. Flood severity is represented by the ratio of the flooded length of the rivers to the total length of the rivers. Different scenarios for the combinations of rainfalls and tidal levels are modeled by a hydraulic simulation model of the complex river network. The results of the model reveal that flood areas and flood severity provide information for developing the curves of flood severity as a function of rainfall and tidal level.

\subsection{Analysis of joint risk probability of rainfall and tidal level}

For two random variables during the annual maximum rainfall events, annual maximum 24-h rainfall $H$ and the highest tidal level during the annual maximum 24-h rainfall $Z$, the observations $\{h, z\}$ of $H$ and $Z$ from 1952 to 2008 were collected as samples to estimate the joint distribution function of the two variables. Depending on the joint distribution function, the joint probability of any combinations of rainfall and tidal level over some values may be assessed, including the extremes that rainfall and tidal level both exceed certain threshold values.

Copulas are employed to estimate the joint distribution of the two variables, $H$ and $Z$. As presented by Sklar (1959), to obtain a joint cumulative distribution function $F(h, z)$ for $H$ and $Z$ with marginal distributions $F_{h}(h)$ and $F_{z}(z)$, respectively, a copula function $C$ makes $F(h, z)=$ $C\left(F_{h}(h), F_{z}(z)\right)$. The widely used copulas, including Gaussian, $t$, Clayton, Frank, and Gumbel copulas, are introduced in the Appendix A. The parameters of the copulas were 
estimated using the maximum likelihood approach (Wang et al., 2009).

The best-fit copula is selected using ordinary least squares (OLS) criteria and Kolmogorov-Smirnov (K-S) test with the test statistic $D$. The lower the value of OLS or $D$ is, the better the fit by the copula. The OLS is expressed as follows:

$\mathrm{OLS}=\sqrt{\frac{1}{n} \sum_{i=1}^{n}\left(p_{\mathrm{i}}-p_{\mathrm{ei}}\right)^{2}}$,

where $p_{\mathrm{i}}$ and $p_{\text {ei }}$ present the theoretic and empirical frequencies of the joint distribution, respectively.

The $\mathrm{K}-\mathrm{S}$ test is a commonly used non-parametric test whose test statistic $D$ is obtained from the following relationship:

$D=\max _{1 \leq k \leq n}\left\{\left|F\left(h_{k}, z_{k}\right)-\frac{m_{k}}{n}\right|,\left|F\left(h_{k}, z_{k}\right)-\frac{m_{k}-1}{n}\right|\right\}$,

where $F\left(h_{k}, z_{k}\right)$ is the joint distribution value of the $k$-th joint observation, $m_{k}$ is the number of joint observations meeting the conditions $\left\{H \leq h_{k}, Z \leq z_{k}\right\}$ in the joint observation sample, and $n$ is the number of observations.

This study is focused on the probability that extreme events occur, including the following: (a) the probability of $H$ and $Z$ both exceeding certain threshold values, denoted as $P \cap(h, z)$; (b) the probability that $H$ exceeds a specific threshold when $Z$ is also high, denoted as $P(H>h \mid Z>z)$; and (c) the probability that at least one variable, $H$ or $Z$, exceeds its threshold values, denoted as $P \cup(h, z)$. These probabilities are obtained from the following relationships:

$$
\begin{aligned}
P \cap(h, z) & =P((H>h) \cap(Z>z)) \\
& =1-F_{h}(h)-F_{z}(z)+F(h, z) ;
\end{aligned}
$$

$$
\begin{aligned}
& (H>h \mid Z>z) \\
& \quad=\frac{P \cap(h, z)}{P(Z>z)}=\frac{1-F_{h}(h)-F_{z}(z)+F(h, z)}{1-F_{z}(z)} ; \\
& P \cup(h, z)=P((H>h) \cup(Z>z))=1-F(h, z) .
\end{aligned}
$$

\section{Results and discussion}

\subsection{Verification of the complex river network model}

During Typhoon Longwang in 2005, the Jinan River, its connected rivers, and other rivers near the northern mountains were flooded because of the combined impact of rainfall runoff from the northern mountainous areas and local run-off. The rainfall records, flooded areas due to river inundation, and the operation of tide gates and drainage pumps were recorded, which were translated into boundary conditions

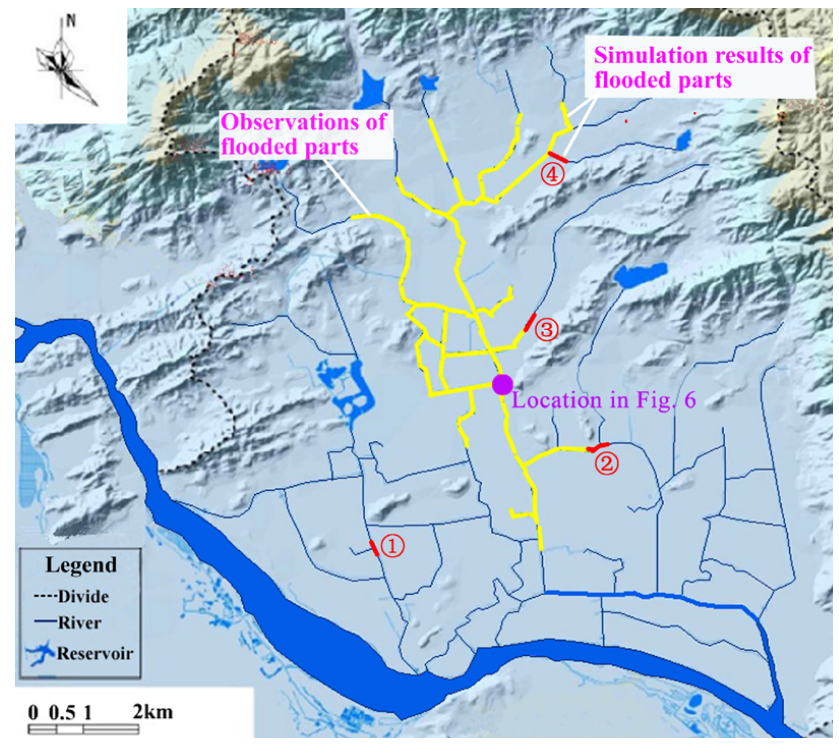

Fig. 5. Comparison of flooded parts of the rivers in Fuzhou City between observed data and the simulation results during Typhoon Longwang on 2 October 2005. Yellow overlays represent the flooded parts of the rivers according to the observed data. Red overlays associated with numbers represent the larger parts of the simulation results compared with the observations. Purple point shows the location where the evaluation is made in Fig. 6.

and information for the verification of the hydraulic simulation model of the complex river network. The small deviation in runoff calculation, the Manning coefficients of the complex river network and some unrecorded operations may cause a small difference between the modeled results and the observed data.

Flow routing and velocity, river levels, and areas flooded by the river were modeled and compared with the observed data presented in Fig. 5. The areas flooded by the river that were modeled match the observations very well, the same part shown with thick overlays in yellow color and four small differences indicated by the red overlays. As shown in Fig. 6 the modeled level hydrograph at the confluence of the Jinan and Wusi Rivers (the purple point in Fig. 5) also agrees with the observed data with the same trend and highest value. Therefore, as mentioned above, the hydraulic simulation model of the complex river network is validated, especially for use in scenario modeling.

\subsection{Joint impact of rainfall and tidal level on flooding}

As previously mentioned, flood severity is subject to the joint influence of rainfall, the tidal level of the receiving body of water, and the operation of drainage facilities, such as tide gates and pumps for a coastal city. In this study, flow movement and flood severity under different combinations of rainfalls and tidal levels were simulated using the calibrated model with two kinds of operational conditions, namely, with 


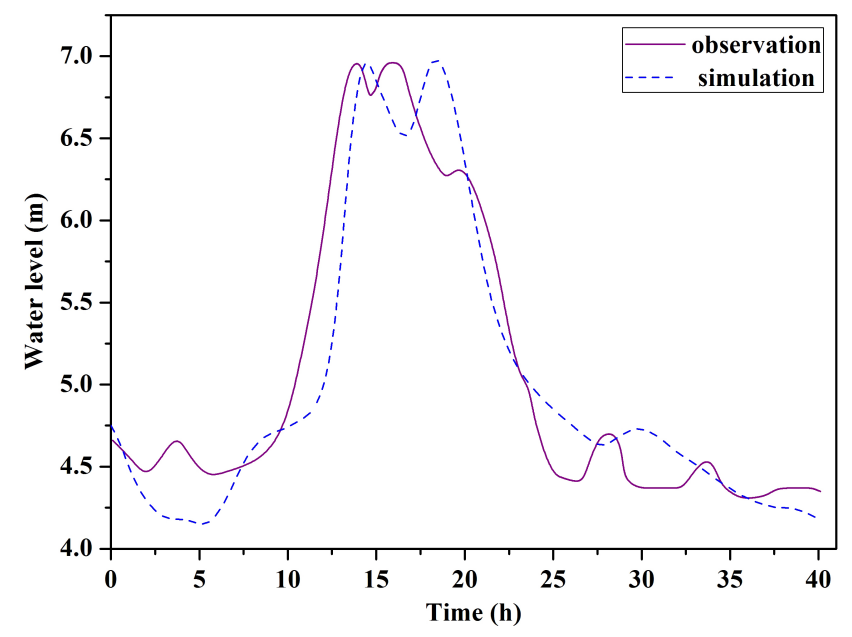

Fig. 6. Comparison of level hydrographs between the observed data and the simulation results at the confluence of Jinan River and Wusi River (shown with purple point in Fig. 5).

and without working pumps. For each operational condition, the isolines of flood severity are presented as a function of rainfall and tidal level not only in terms of absolute values (Fig. 7a) but also in terms of RPs (Fig. 7b). The threshold condition of the simple occurrence of flood is presented with red lines.

The combination of rainfall and tidal level and the percentage of the total river length flooded during Typhoon Longwang are presented by a point in Fig. 7a. The comparison between the point and the isoline representing $25 \%$ of the length of the flooded area demonstrates the reliability of the isolines. The isolines indicate that the factors influencing flood occurrence and severity are precipitation, the tidal level, operational mode of drainage facilities, and the characteristics of the river network. The characteristics of the river network contain conveyance capacity, division and convergence of flow, and regulation and storage capacity.

Figure $7 \mathrm{~b}$ indicates that working pumps efficiently reduce flood risk within a 20-yr RP precipitation in Fuzhou. However, when the rainfall exceeds a 100-yr RP, the pumps may not help effectively because of the restrictions of the river conveyance capacity. For example, the tidal level for flood occurrence is a 29.8 -yr RP in working pump conditions for a rainfall with a 5-yr RP, which is just a 2.2-yr RP without pumping (Fig. 7b). However, for a rainfall with a 100-yr RP, the corresponding tidal levels both are 1.0-yr RP.

For Fuzhou, a 100-yr RP is a critical value with the current pumping capacity. When the precipitation is lower than this value, pumping is useful; otherwise, pumping is almost useless. Flood happens when the flood discharge exceeds the flow capacity of the rivers. In this situation, pumps with a certain capacity located downstream of a river network have a limited effect on reducing flood. High-capacity pumps may
Table 1. Extreme values for rainfall and tidal level as a function of return period. The tidal level is measured using the Luo Zero Vertical Datum of China.

\begin{tabular}{ccc}
\hline $\begin{array}{c}\text { Return } \\
\text { period (yr) }\end{array}$ & $\begin{array}{c}\text { Maximum 24-h } \\
\text { rainfall }(\mathrm{mm})\end{array}$ & $\begin{array}{c}\text { Tidal } \\
\text { level }(\mathrm{m})\end{array}$ \\
\hline 2 & 112.5 & 7.32 \\
5 & 143.4 & 8.13 \\
10 & 169.8 & 8.58 \\
20 & 194.6 & 8.97 \\
50 & 226.1 & 9.39 \\
100 & 265.8 & 9.77 \\
\hline
\end{tabular}

still not be helpful. For other cities, the critical value is probably different because of the difference in the drainage system.

\subsection{Joint probability analysis}

\subsubsection{Marginal distributions}

As for the annual maximum daily rainfall $H$ and the highest tidal level within the day of annual maximum daily rainfall $Z$, their marginal distributions $F_{h}(h)$ and $F_{z}(z)$ are fitted using Pearson type-III (P-III) distribution. The comparison of empirical and theoretical distributions for $H$ and $Z$ is plotted in Figs. 8 and 9a, respectively, indicating that the theoretical distributions fit the observation data very well. According to the theoretical cumulative distribution function (CDF) of $H$, the RPs of extreme rainfalls were estimated (Table 1). The RPs of the extreme tidal levels estimated through the CDF of the annual maximum tidal levels, rather than the $\operatorname{CDF}$ of $Z$, are shown in Table 1.

\subsubsection{Goodness-of-fit test}

The copula parameters in Eqs. (A1) to (A5), presented in the Appendix A, were calculated using the maximum likelihood approach (Table 2). The copula functions are defined by these parameters. $D$ and OLS, obtained from Eqs. (2) and (1), are shown in Table 2. At a significance level of $\alpha=0.05$, the value $D$ of each copula function can pass the $\mathrm{K}-\mathrm{S}$ test. The $D$ and OLS of the Gumbel copula are the smallest of all the copulas (Table 2), indicating that the Gumbel copula function best fits the joint distribution of rainfall and tidal level. Accordingly, the linear correlation coefficient between empirical and theoretical distributions of the joint probabilities is very high, up to 0.9982 .

According to the parameters calculated in Table 2 and Eq. (A5), the Gumbel copula fitting the joint distribution $F(h, z)$ for $H$ and $Z$ can be expressed as

$$
\begin{aligned}
F(h, z) & =\exp \left\{-\left[\left(-\ln F_{h}(h)\right)^{1.0581}\right.\right. \\
& \left.\left.+\left(-\ln F_{z}(z)\right)^{1.0581}\right]^{1 / 1.0581}\right\} .
\end{aligned}
$$



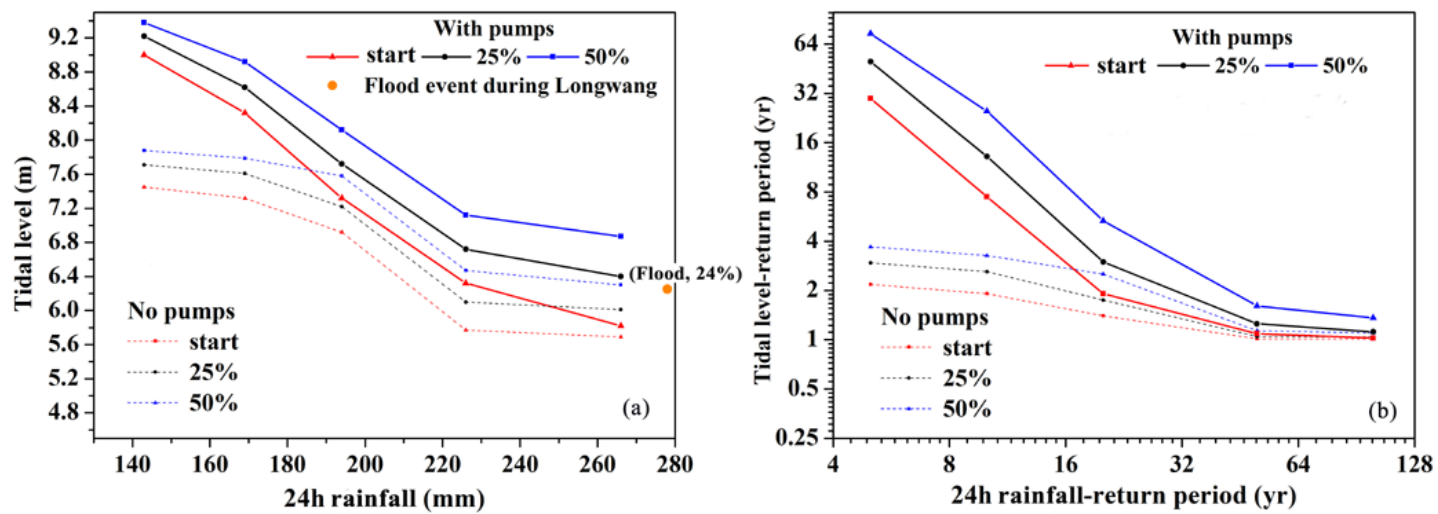

Fig. 7. Isolines of flood severity as a function of 24-h rainfall and tidal level with and without working pumps, shown as two forms of variables: (a) in terms of absolute values and (b) in terms of RPs. Severity is measured as the percentage of the total river length that is flooded. The event \# and the percentage are in brackets. The isoline "start" indicates the conditions at the instant that the flooding threshold is crossed.

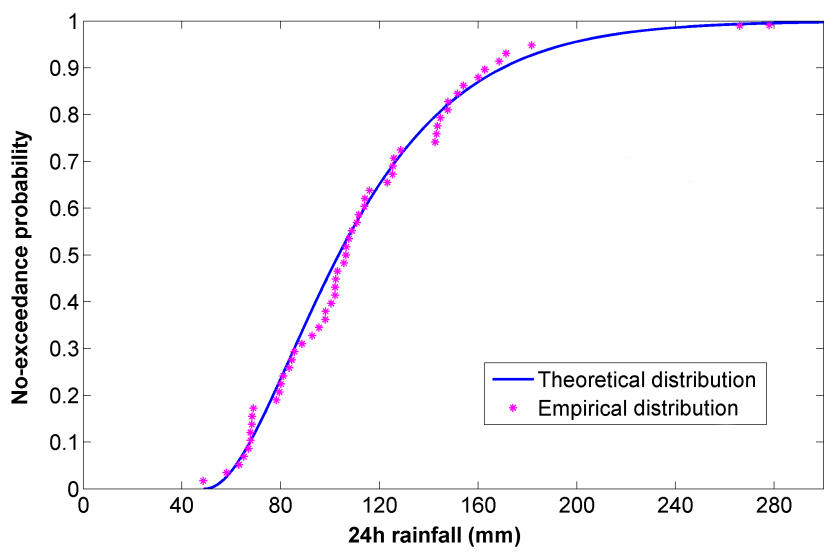

Fig. 8. Comparison of empirical and theoretical distributions for the annual maximum 24-h rainfall.

\subsubsection{Joint risk probability analysis}

This study focuses on the probability that extreme events occur, that is, on the probability of variables exceeding some RPs. For an annual maximum rainfall $H$, the exceedance probability $P_{1}$ and the RP value $T_{1}$ can be estimated using the marginal distribution (see Sect. 4.3.1). For a tidal level, an exceedance probability $P_{2}$ in terms of the CDF of $\mathrm{Z}$ exists, as well as another exceedance probability $P_{M}$ in terms of the CDF of the annual maximum tidal level. According to the CDF of the annual maximum tidal level, the RP value $T_{M}$ for this tidal level can be estimated and vice versa. For example, for a tidal level of $7.32 \mathrm{~m}$, its exceedance probability $P_{2}$ in terms of the CDF of $Z$ is $1.41 \%$ (green point in Fig. 9a). Meanwhile, another exceedance probability $P_{M}$ in terms of the CDF of the annual maximum tidal level is $50 \%$ (green point in Fig. 9b), and the RP value $T_{M}$ is 2 yr. When we know the tidal level values for some RPs, we can estimate
Table 2. Parameters and goodness-of-fit test of copulas.

\begin{tabular}{llll}
\hline Copulas & parameters & $D$ & OLS \\
\hline Gumbel Copula & $\theta=1.0581$ & 0.0602 & 0.01603 \\
Clayton Copula & $\theta=0.1291$ & 0.0660 & 0.01699 \\
Frank Copula & $\theta=0.5326$ & 0.0641 & 0.01691 \\
Gaussian Copula & $\rho=0.1105$ & 0.0657 & 0.01784 \\
$t$ Copula & $\rho=0.1069$ & 0.0654 & 0.01699 \\
\hline
\end{tabular}

the joint probabilities of the tidal level and rainfall with some RPs by the joint CDF of $H$ and $Z$.

For each given combination of $H$ and $Z$, the joint distribution $F(h, z)$ can be estimated through Eq. (6). Accordingly, the risk probabilities $P \cap(h, z), P(H>h \mid Z>z)$, and $P \cup(h, z)$ can be obtained from Eqs. (3), (4), and (5) based on $F_{h}(h), F_{z}(z)$, and $F(h, z)$ (Table 3 ).

The column $P \cap(h, z)$ shown in Table 3 indicates that the joint probability of a 5-yr RP rainfall and 2-yr RP tidal level is $0.5017 \%$ per year. With increasing RP of rainfall or tidal level, the joint probability decreases, implying that heavy rains and high tidal levels barely happen simultaneously. Flood in Fuzhou is caused mainly by intense rainfall. To see this, suppose two numbers: A and B. If $\mathrm{A}$ is larger than $\mathrm{B}$, the encounter probability of the precipitation of A-yr RP and the tidal level of B-yr RP is higher than that of the tidal level of A-yr RP and the precipitation of B-yr RP (Fig. 10). For example, the encounter probability of a 50-yr RP rainfall and 5-yr RP tidal level is $0.0546 \%$ per year, whereas the occurrence probability of a 50-yr RP tidal level and 5-yr RP rainfall is $0.0146 \%$ per year. This is consistent with actual occurrences. The flood caused by Typhoon Longwang is a typical example.

The parameter $\rho$ representing the linear dependence between $H$ and $Z$ is greater than zero (Table 2), which clearly indicates that some positive dependence exists between $H$ 

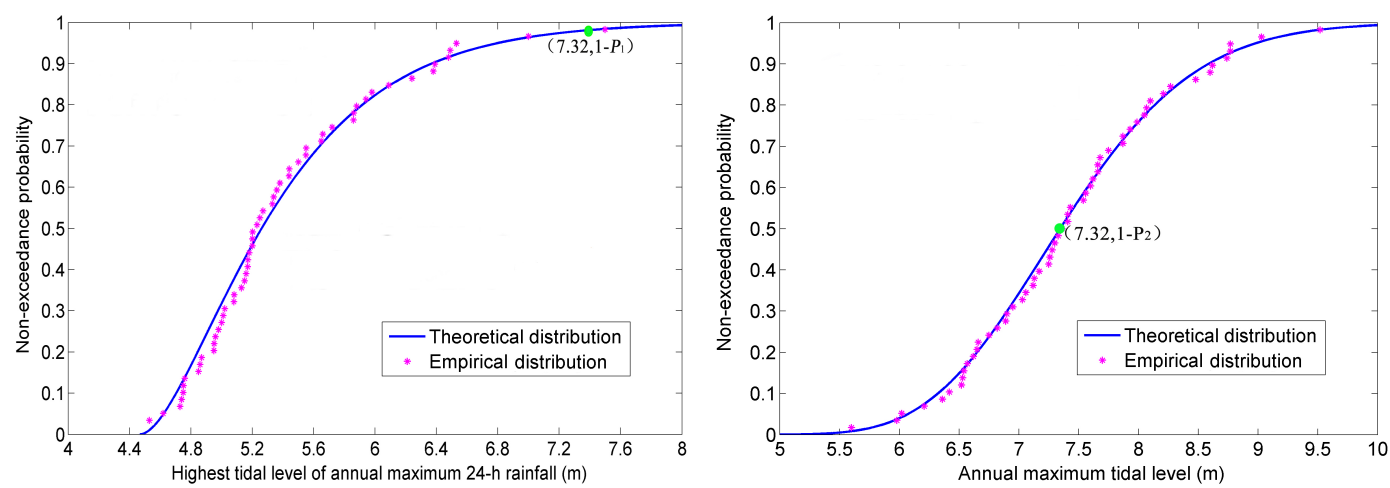

Fig. 9. Comparison of the empirical and theoretical distributions for the highest tidal level during the annual maximum 24-h rainfall and the annual maximum tidal level, respectively.

Table 3. Risk probabilities of different encounter conditions. $H$ : annual maximum 24-h rainfall; $P_{1}$ : exceedance probability of $H$ in CDF of $H$; $T$ : return period of $H ; Z$ : highest tidal level within the day of $H ; P_{2}$ : exceedance probability of $Z$ in $C D F$ of $Z$; $P_{M}$ : exceedance probability of $Z$ in distribution of annual maximum tidal level; $T_{M}$ : return period of $Z ; F(h, z)$ : joint $\mathrm{CDF}$ for $H$ and $Z$.

\begin{tabular}{|c|c|c|c|c|c|c|c|c|c|c|}
\hline \multicolumn{7}{|c|}{ Encounter conditions } & \multirow[b]{3}{*}{$\begin{array}{c}F \\
(h, z)\end{array}$} & \multirow[b]{3}{*}{$\begin{array}{l}P \cap(h, z) \\
\left(\% \mathrm{yr}^{-1}\right)\end{array}$} & \multirow[b]{3}{*}{$\begin{array}{c}P(H>h \mid Z>z) \\
\left(\% \mathrm{yr}^{-1}\right)\end{array}$} & \multirow[b]{3}{*}{$\begin{array}{l}P \cup(h, z) \\
\left(\% \mathrm{yr}^{-1}\right)\end{array}$} \\
\hline \multicolumn{3}{|c|}{ Annual Maximum 24-h rainfall } & \multicolumn{4}{|c|}{$\begin{array}{l}\text { Highest tidal level during } \\
\text { annual maximum 24-h rainfall }\end{array}$} & & & & \\
\hline $\begin{array}{c}H \\
(\mathrm{~mm})\end{array}$ & $\begin{array}{c}P_{1} \\
(\%)\end{array}$ & $\begin{array}{c}T \\
(\mathrm{yr})\end{array}$ & $\begin{array}{c}Z \\
(\mathrm{~m})\end{array}$ & $\begin{array}{c}P_{2} \\
(\%)\end{array}$ & $\begin{array}{l}P_{M} \\
(\%)\end{array}$ & $\begin{array}{l}T_{M} \\
(\mathrm{yr})\end{array}$ & & & & \\
\hline 226.1 & 2 & 50 & 9.39 & 0.03 & 2 & 50 & 0.9798 & 0.0082 & 27.4966 & 2.0218 \\
\hline 226.1 & 2 & 50 & 8.97 & 0.06 & 5 & 20 & 0.9795 & 0.0147 & 24.5400 & 2.0453 \\
\hline 226.1 & 2 & 50 & 8.58 & 0.14 & 10 & 10 & 0.9789 & 0.0291 & 20.7997 & 2.1109 \\
\hline 226.1 & 2 & 50 & 8.13 & 0.32 & 20 & 5 & 0.9773 & 0.0546 & 17.0668 & 2.2654 \\
\hline 226.1 & 2 & 50 & 7.32 & 1.41 & 50 & 2 & 0.9674 & 0.1496 & 10.6076 & 3.2604 \\
\hline 194.6 & 5 & 20 & 9.39 & 0.03 & 2 & 50 & 0.9498 & 0.0100 & 33.4061 & 5.0200 \\
\hline 194.6 & 5 & 20 & 8.97 & 0.06 & 5 & 20 & 0.9496 & 0.0184 & 30.6752 & 5.0416 \\
\hline 194.6 & 5 & 20 & 8.58 & 0.14 & 10 & 10 & 0.9490 & 0.0381 & 27.1954 & 5.1019 \\
\hline 194.6 & 5 & 20 & 8.13 & 0.32 & 20 & 5 & 0.9476 & 0.0757 & 23.6611 & 5.2443 \\
\hline 194.6 & 5 & 20 & 7.32 & 1.41 & 50 & 2 & 0.9383 & 0.2416 & 17.1374 & 6.1684 \\
\hline 169.8 & 10 & 10 & 9.39 & 0.03 & 2 & 50 & 0.8998 & 0.0118 & 39.4910 & 10.0182 \\
\hline 169.8 & 10 & 10 & 8.97 & 0.06 & 5 & 20 & 0.8996 & 0.0222 & 37.0051 & 10.0378 \\
\hline 169.8 & 10 & 10 & 8.58 & 0.14 & 10 & 10 & 0.8991 & 0.0474 & 33.8296 & 10.0926 \\
\hline 169.8 & 10 & 10 & 8.13 & 0.32 & 20 & 5 & 0.8978 & 0.0979 & 30.5850 & 10.2221 \\
\hline 169.8 & 10 & 10 & 7.32 & 1.41 & 50 & 2 & 0.8893 & 0.3447 & 24.4442 & 11.0653 \\
\hline 143.4 & 20 & 5 & 9.39 & 0.03 & 2 & 50 & 0.7998 & 0.0146 & 48.5071 & 20.0154 \\
\hline 143.4 & 20 & 5 & 8.97 & 0.06 & 5 & 20 & 0.7997 & 0.0278 & 46.3896 & 20.0322 \\
\hline 143.4 & 20 & 5 & 8.58 & 0.14 & 10 & 10 & 0.7992 & 0.0612 & 43.6813 & 20.0788 \\
\hline 143.4 & 20 & 5 & 8.13 & 0.32 & 20 & 5 & 0.7981 & 0.1309 & 40.9053 & 20.1891 \\
\hline 143.4 & 20 & 5 & 7.32 & 1.41 & 50 & 2 & 0.7909 & 0.5017 & 35.5791 & 20.9083 \\
\hline
\end{tabular}

and $Z$. The conditional probability $P(H>h \mid Z>z)$ is relatively large and always larger than the exceedance probability of $H, P_{1}$, which verifies the positive dependence between $H$ and $Z$. Thus, a high tidal level is usually accompanied by heavy rains, even though the occurrence probability of rainfall and tidal level both exceeding their threshold values is very low.
According to the analysis in Sect. 4.2, a single source, either a heavy rain or a high tidal level, could cause flooding and influence flood severity. Thus, a quantitative analysis of the probability that at least one variable exceeds its threshold is necessary. The values of $P(H>h \cup Z>z)$ are slightly larger than the exceedance probability of rainfall, $P_{1}$, illustrating that the tidal level poses an extra risk of flooding. Given that this extra risk is ignored in the design of flood 


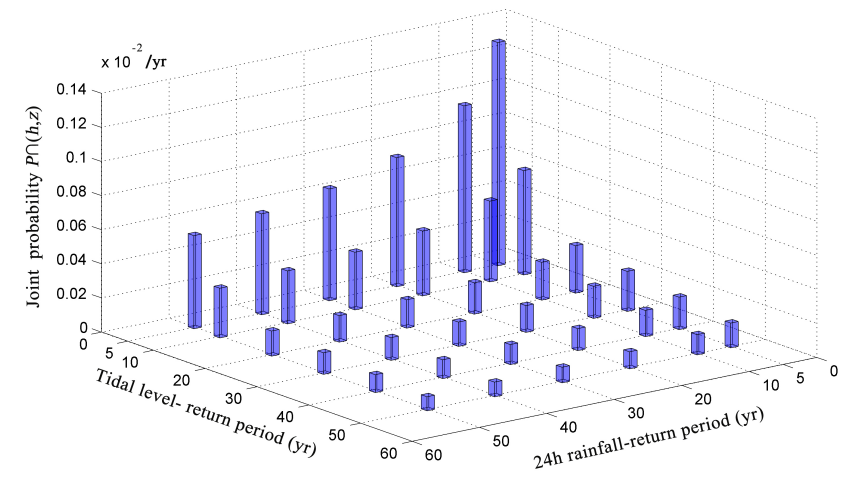

Fig. 10. Bar graph of joint probability, $P \cap(h, z)$, as a function of the RP of rainfall and tidal level.

defense in Fuzhou, flood frequency and severity will increase in the future. The feasible scheduling rules of tide gates and efficient pumping upstream to reduce flood volume, thus reducing the risk, in the river network are effective measures.

\section{Conclusions}

The current work was performed to assess the joint impact of rainfall and downstream tidal level on flood risk in a coastal city with a complex river network. The work is split into three main parts: (a) the establishment of a hydrodynamic model for the complex river network in Fuzhou; (b) the assessment of flood severity under the combined impact of precipitation intensities and tidal levels; and (c) the joint risk analysis of rainfall and tidal level exceeding their threshold values.

The model of the complex river network was established to investigate the combined effects of rainfalls and tidal levels on flood occurrence and severity with and without working pumps. According to the percentages of the river network along which flooding occurs, the isolines of equal flood severity as a function of rainfall and tidal level are estimated and verified by the flood data collected during Typhoon Longwang, providing possible prediction information for the effects of climate change. As the isolines show, a threshold value of precipitation exists for efficient flood risk reduction by pumps working for a coastal city. This threshold value is a 20-yr RP for Fuzhou. However, when the tidal level reaches a certain standard, the outlet sluice will not work, and the discharge of the pumping decreases. Subsequently, a flood occurs if the water volume from rainfall exceeds the regulation and storage capacity of the river network. When precipitation reaches a certain standard, no matter what the tidal level is, the flood occurs because of the restriction of a river conveyance capacity. That is, another threshold value of precipitation with which pumps cannot take effect on flood risk efficiently also exists. Therefore, controlling flood simply by increasing pumping capacity is inadvisable, and un- derstanding these thresholds would be helpful in taking reasonable measures for flood risk management.

The joint risk probability of rainfall and tidal level exceeding their thresholds was also analyzed based on the copula function. The occurrence probability of rainfall and tidal level both exceeding their threshold values is very low in Fuzhou, and the maximum joint probability is $0.5017 \%$ per year. However, some positive dependence exists between $H$ and $Z$, implying that tidal level poses an extra risk of flooding. Given that the flood defense design in Fuzhou currently ignores this extra risk, flood frequency and the cost due to floods will rise in the future. The design of flood defenses should take into account this extra risk based on the quantitative analysis of the joint risk probability to reduce such incidences.

In this study, the flood consequences were estimated using the percentage of the river network where flooding occurs. A more detailed analysis and discussion of flood consequence, such as economic loss and casualties, can be undertaken. Moreover, combining the impact of flood probability and consequence into a single risk function will be the topic of future research.

\section{Appendix A}

The widely used copulas, including Gaussian, $t$, Clayton, Frank, and Gumbel copulas, are introduced as follows:

a. The Gaussian copula is as follows:

$$
\begin{gathered}
C(u, v)=\int_{-\infty}^{\Phi^{-1}(u) \Phi_{-\infty}^{-1}(v)} \frac{1}{2 \pi \sqrt{1-\rho^{2}}} \exp \\
\left(\frac{-\left(r^{2}+s^{2}-2 \rho r s\right)}{2\left(1-\rho^{2}\right)}\right) \mathrm{d} r \mathrm{~d} s, \rho \in(-1,1),
\end{gathered}
$$

where $u$ and $v$ are the dummy variables of the marginal distributions, $\Phi^{-1}(\cdot)$ is the inverse function of the standard normal distribution function $\Phi(\cdot)$, and $\rho$ is the linear correlation coefficient between $\Phi^{-1}(u)$ and $\Phi^{-1}(v)$;

b. the $t$ copula is given as

$$
\begin{aligned}
& C(u, v, \rho, \alpha)=\int_{-\infty}^{T_{\alpha}^{-1}(u)} \int_{-\infty}^{T_{\alpha}^{-1}(v)} \frac{1}{2 \pi \sqrt{1-\rho^{2}}} \exp \\
& \left(1+\frac{r^{2}+s^{2}-2 \rho r s}{\alpha(1-\rho)^{2}}\right)^{-\frac{\alpha+2}{2}} \mathrm{~d} r \mathrm{~d} s, \rho \in(-1,1),(\mathrm{A} 2)
\end{aligned}
$$

where $T_{\alpha}^{-1}(\cdot)$ is the inverse function of the distribution function $T_{\alpha}(\cdot)$ with $\alpha$ as the degree of freedom, and $\rho$ as the linear correlation coefficient between $T_{\alpha}^{-1}(u)$ and $T_{\alpha}^{-1}(v)$ 
c. the Clayton copula is expressed as

$$
C(u, v)=\left(u^{-\theta}+v^{-\theta}-1\right)^{-1 / \theta}, \theta \in(0, \infty),
$$

where $\theta$ is the parameter;

d. the Frank copula is

$$
\begin{aligned}
C(u, v) & =-\frac{1}{\theta} \ln \left[1+\frac{\left(e^{-\theta u}-1\right)\left(e^{-\theta v}-1\right)}{e^{-\theta}-1}\right], \\
\theta \in R \backslash\{0\} ; &
\end{aligned}
$$

and

e. the expression of Gumbel copula is

$C(u, v)=\exp \left\{-\left[(-\ln u)^{\theta}+(-\ln v)^{\theta}\right]^{1 / \theta}\right\}, \theta \in[1, \infty)$.

Acknowledgements. The research was supported by the Science Fund for Creative Research Groups of the National Natural Science Foundation of China (51021004), National Natural Science Foundation of China (51109156), Major National Science and Technology Project ( 2012ZX07205-005), Specialized Research Fund for the Doctoral Program of Higher Education (20100032120048). The authors acknowledge Xiaozhong Sun and Ting Zhang for their work in data collection and analysis. The authors are very grateful to Ying Li for the help in the formation of this paper. The authors also acknowledge the assistance of anonymous reviewers.

Edited by: B. van den Hurk

\section{References}

Adelekan, I. O.: Vulnerability assessment of an urban flood in Nigeria: Abeokuta flood 2007, Nat. Hazards, 56, 215-231, doi:10.1007/s11069-010-9564-z, 2010.

AghaKouchak, A., Bárdossy, A., and Habib, E.: Conditional simulation of remotely sensed rainfall data using a nonGaussian v-transformed copula, Adv. Water Resour., 33, 624634, doi:10.1016/j.advwatres.2010.02.010, 2010.

Apel, H., Aronica, G. T., Kreibich, H., and Thieken, A. H.: Flood risk analyses - how detailed do we need to be?, Natural Hazards, 49, 79-98, doi:10.1007/s11069-008-9277-8, 2008.

Archetti, R., Bolognesi, A., Casadio, A., and Maglionico, M.: Development of flood probability charts for urban drainage network in coastal areas through a simplified joint assessment approach, Hydrol. Earth Syst. Sci., 15, 3115-3122, doi:10.5194/hess-153115-2011, 2011.

Bacchi, B., Becciu, G., and Kottegoda, N. T.: Bivariate exponential model applied to intensities and durations of extreme rainfall, J. Hydrol., 155, 225-236, 1994.

Balistrocchi, M. and Bacchi, B.: Modelling the statistical dependence of rainfall event variables through copula functions, Hydrol. Earth Syst. Sci., 15, 1959-1977, doi:10.5194/hess-15-19592011, 2011.

Bárdossy, A. and Pegram, G. G. S.: Copula based multisite model for daily precipitation simulation, Hydrol. Earth Syst. Sci., 13, 2299-2314, doi:10.5194/hess-13-2299-2009, 2009.
Chang, H., Franczyk, J., and Kim, C.: What is responsible for increasing flood risks? The case of Gangwon Province, Korea, Nat. Hazards, 48, 339-354, doi:10.1007/s11069-008-9266-y, 2008.

Cheng, C. T., Zhao, M. Y., Chau, K. W., and Wu, X. Y.: Using genetic algorithm and TOPSIS for Xinanjiang model calibration with a single procedure, J. Hydrol., 316, 129-140, 2006.

Dawson, R., Hall, J., Sayers, P., Bates, P., and Rosu, C.: Samplingbased flood risk analysis for fluvial dike systems, Stoch. Environ. Res. Risk Assess., 19, 388-402, doi:10.1007/s00477-005-00109, 2005.

Dawson, R. J., Speight, L., Hall, J. W., Djordjevic, S., Savic, D., and Leandro, J.: Attribution of flood risk in urban areas, J. Hydroinform., 10, 275-288, doi:10.2166/hydro.2008.054, 2008.

De Michele, C., Salvadori, G., Passoni, G., and Vezzoli, R.: A multivariate model of sea storms using copulas, Coast. Eng., 54, 734 751, doi:10.1016/j.coastaleng.2007.05.007, 2007.

Ernst, J., Dewals, B. J., Detrembleur, S., Archambeau, P., Erpicum, S., and Pirotton, M.: Micro-scale flood risk analysis based on detailed 2D hydraulic modelling and high resolution geographic data, Nat. Hazards, 55, 181-209, doi:10.1007/s11069-010-9520y, 2010

Fan, C., Ko, C. H., and Wang, W. S.: An innovative modeling approach using Qual2K and HEC-RAS integration to assess the impact of tidal effect on River Water quality simulation, J. Environ. Manage., 90, 1824-1832, doi:10.1016/j.jenvman.2008.11.011, 2009.

Grimaldi, S. and Serinaldi, F.: Asymmetric copula in multivariate flood frequency analysis, Adv. Water Resour., 29, 1155-1167, doi:10.1016/j.advwatres.2005.09.005, 2006.

Guo, J.: Rational Hydrograph Method for Small Urban Watersheds, J. Hydrol. Eng., 6, 352-356, doi:10.1061/(ASCE)10840699(2001)6:4(352), 2001.

Hadjimitsis, D. G.: Brief communication "Determination of urban growth in catchment areas in Cyprus using multi-temporal remotely sensed data: risk assessment study", Nat. Hazards Earth Syst. Sci., 10, 2235-2240, doi:10.5194/nhess-10-22352010, 2010.

Hall, J. W., Sayers, P. B., and Dawson, R. J.: National-scale assessment of current and future flood risk in England and Wales, Nat. Hazards, 36, 147-164, 2005.

Hu, C., Guo, S., Xiong, L., and Peng, D.: A modified Xinanjiang model and its application in northern China, Nord. Hydrol., 36, 175-192, 2005.

Kelly, K. S. and Krzysztofowicz, R.: A bivariate meta-Gaussian density for use in hydrology, Stoch. Hydrol. Hydraul., 11, 1731, 1997.

Knebl, M. R., Yang, Z. L., Hutchison, K., and Maidment, D. R.: Regional scale flood modeling using NEXRAD rainfall, GIS, and HEC-HMS/RAS: a case study for the San Antonio River Basin Summer 2002 storm event, J. Environ. Manage., 75, 325-336, doi:10.1016/j.jenvman.2004.11.024, 2005.

Kok, J.-L. and Grossmann, M.: Large-scale assessment of flood risk and the effects of mitigation measures along the Elbe River, Nat Hazards, 52, 143-166, doi:10.1007/s11069-009-9363-6, 2009.

Lee, K. T., Ho, Y. H., and Chyan, Y. J.: Bridge Blockage and Overbank Flow Simulations Using HEC-RAS in the Keelung River during the 2001 Nari Typhoon, J. Hydraul. Eng., 132, 319-323, 2006. 
Long, D. and Krzysztofowicz, R.: Farlie-Gumbel-Morgenstern bivariate densities: Are they applicable in hydrology?, Stoch. Hydrol. Hydraul., 6, 47-54, 1992.

Mazzorana, B., Comiti, F., Scherer, C., and Fuchs, S.: Developing consistent scenarios to assess flood hazards in mountain streams, J. Environ. Manage., 94, 112-124, doi:10.1016/j.jenvman.2011.06.030, 2012.

Merz, B., Kreibich, H., Schwarze, R., and Thieken, A.: Review article "Assessment of economic flood damage", Nat. Hazards Earth Syst. Sci., 10, 1697-1724, doi:10.5194/nhess-10-16972010, 2010.

Ngo, L. L., Madsen, H., Rosbjerg, D., and Pedersen, C. B.: Implementation and Comparison of Reservoir Operation Strategies for the Hoa Binh Reservoir, Vietnam using the Mike 11 Model, Water Resour. Manag., 22, 457-472, doi:10.1007/s11269-0079172-1, 2007.

Ni, J., Sun, L., Li, T., Huang, Z., and Borthwick, A. G.: Assessment of flooding impacts in terms of sustainability in Mainland China, J. Environ. Manage., 91, 1930-1942, doi:10.1016/j.jenvman.2010.02.010, 2010.

Pathirana, A., Tsegaye, S., Gersonius, B., and Vairavamoorthy, K.: A simple 2-D inundation model for incorporating flood damage in urban drainage planning, Hydrol. Earth Syst. Sci., 15, $2747-$ 2761, doi:10.5194/hess-15-2747-2011, 2011.

Plate, E. J.: Flood risk and flood management, J. Hydrol., 267, 2-11, 2002.

Ren-Jun, Z.: The Xinanjiang model applied in China, J. Hydrol., 135, 371-381, 1992.

Renard, B. and Lang, M.: Use of a Gaussian copula for multivariate extreme value analysis: Some case studies in hydrology, Adv. Water Resour., 30, 897-912, doi:10.1016/j.advwatres.2006.08.001, 2007.

Rodriguez, L. B., Cello, P. A., Vionnet, C. A., and Goodrich, D.: Fully conservative coupling of HEC-RAS with MODFLOW to simulate stream - aquifer interactions in a drainage basin, J. Hydrol., 353, 129-142, doi:10.1016/j.jhydrol.2008.02.002, 2008.
Rulli, M. C. and Rosso, R.: An integrated simulation method for flash-flood risk assessment: 1. Frequency predictions in the Bisagno River by combining stochastic and deterministic methods, Hydrol. Earth Syst. Sci., 6, 267-284, doi:10.5194/hess-6-2672002, 2002.

Samuels, P., Klijn, F., and Dijkman, J.: An analysis of the current practice of policies on river flood risk management in different countries, Irrig. Drain., 55, S141-S150, doi:10.1002/ird.257, 2006.

Skaugen, T.: Modelling the spatial variability of snow water equivalent at the catchment scale, Hydrol. Earth Syst. Sci., 11, 15431550, doi:10.5194/hess-11-1543-2007, 2007.

Sklar, A.: Fonctions de répartition à $\mathrm{n}$ dimensions et leurs marges, Publ. Inst. Statist. Univ. Paris, 8, 229-231, 1959.

te Linde, A. H., Bubeck, P., Dekkers, J. E. C., de Moel, H., and Aerts, J. C. J. H.: Future flood risk estimates along the river Rhine, Nat. Hazards Earth Syst. Sci., 11, 459-473, doi:10.5194/nhess-11-459-2011, 2011.

van den Berg, M. J., Vandenberghe, S., De Baets, B., and Verhoest, N. E. C.: Copula-based downscaling of spatial rainfall: a proof of concept, Hydrol. Earth Syst. Sci., 15, 1445-1457, doi:10.5194/hess-15-1445-2011, 2011

Wang, C., Chang, N.-B., and Yeh, G.-T.: Copula-based flood frequency (COFF) analysis at the confluences of river systems, Hydrol. Process., 23, 1471-1486, doi:10.1002/hyp.7273, 2009.

Wang, C., Wan, T. R., and Palmer, I. J.: Urban flood risk analysis for determining optimal flood protection levels based on digital terrain model and flood spreading model, Vis. Comput., 26, 1369-1381, doi:10.1007/s00371-009-0414-5, 2010.

Youssef, A. M., Pradhan, B., and Hassan, A. M.: Flash flood risk estimation along the St. Katherine road, southern Sinai, Egypt using GIS based morphometry and satellite imagery, Environ. Earth Sci., 62, 611-623, doi:10.1007/s12665-010-0551-1, 2010.

Yue, S., Ouarda, T., Bobée, B., Legendre, P., and Bruneau, P.: The Gumbel mixed model for flood frequency analysis, J. Hydrol., 226, 88-100, 1999. 